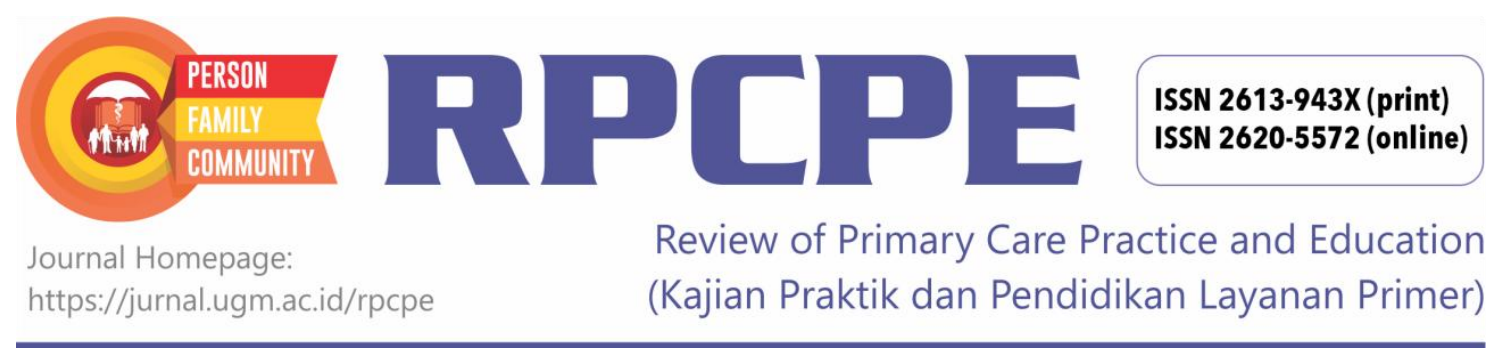

\title{
The Effect of Family APGAR Score on Depression Rate in Type 2 Diabetes Mellitus Patients at First-Level Health Facilities
}

\author{
Annafsul Mutmainah ${ }^{1}$, Hari Kusnanto ${ }^{2}$, Oryzati Hilman ${ }^{3}$
}

\author{
${ }^{1}$ Sedayu 1 Community and Primary Health Care Center; Bantul; Yogyakarta; Indonesia \\ ${ }^{2}$ Department of Family and Community Medicine; Faculty of Medicine, Public Health and Nursing; Universitas Gadjah Mada; \\ Indonesia \\ ${ }^{3}$ Medicine and Health Science Department; Faculty of Medicine; Universitas Muhammadiyah Yogyakarta; Indonesia \\ Corresponding Author \\ Annafsul Mutmainah: Sedayu 1 Community and Primary Health Care Center, Panggang Agromulyo Sedayu, Bantul, Yogyakarta - \\ 55752, Indonesia \\ Email: annafsul.m@gmail.com
}

To cite this article:

Mutmainah A, Kusnanto H, Hilman O. The effect of family apgar score on depression rate in type 2 diabetes mellitus patients at firstlevel health facilities. Rev Prim Care Prac and Educ. 2018; 1(2): 62-68.

\begin{abstract}
Background: Diabetes Mellitus (DM) is a group of degenerative diseases. The prevalence of DM is increasing from year after year. The uncontrolled blood sugar level is associated with the incidence of depression in patients with type 2 diabetes mellitus (T2DM). Additionally, depression will increase the risk of micro and macrovascular complications, disability, and mortality. A functional family is needed for the successful treatment of T2DM patients. A family function assessment should be performed by a family physician as an effort to prevent the occurrence of depression. Family APGAR scores have been widely known among family medicine practitioners as a simple and fast tool for measuring the function of a family. Objectives: To determine the effect of family APGAR scores on the level of depression in patients with T2DM in first-level health facilities. Methods: This study is a quantitative analytic research with a cross-sectional design. A total of 98 T2DM patients as research subjectswere measured using family APGAR score questionnaires. The result of the statistical analysis showed a significant effect of family APGAR scores on depression, with correlation strength (0.364). Furthermore, the research subjects underwent measurement of the depression level by using the HAD (Hospital Anxiety and Depression) scale. Linear regression analysis was used to determine the effect of the family APGAR score and other factors on the level of depression. Results: Data collection from six first-level health facilities obtained 98 samples. Linear regression statistical analysis showed that there is a significant effect of family APGAR scores and age towards the level of depression with sig $<0.05$ (0.000). Family APGAR scores and age contributed $10.6 \%$ in predicting the depression in the T2DM patient. Another $89.4 \%$ is explained by other factors whichwere not studied in this research. Conclusion: There is a significant effect of family APGAR scores and age on the level of depression in a T2DM patient in first-level health facilities.
\end{abstract}

Keywords: APGAR score, family function, type 2 diabetes, depression, HADS

\section{BACKGROUND}

Diabetes Mellitus (DM) is a group of degenerative diseases whose prevalence continues to increase from year after year. The number of cases of adult diabetes in the world reached 171 million people in 2000, an increase of $11 \%$ from the previous estimation. It is estimated that by 2030 the number of DM patients in the world will be 366 million ${ }^{1}$. Basic Health Research (RISKESDAS) in
2013 showed the prevalence of DM in Indonesia increased almost double compared to the year 2007 which was 1.1 percent ${ }^{2}$.

The high number of DM patients is accompanied by increased cases of depression in patients with DM. Several studies have shown that the prevalence of depression in DM patients exceeds the prevalence in the general population. 
Anderson et al. concluded that the prevalence of major depression in DM patients was $11 \% \%^{3}$. A similar number is shown by Collins et al. which was between 10.4-11.2\% ${ }^{4}$. In the Asian region, the prevalence varies from $30 \%$ in Bangladesh $^{5}$ to $14.7 \%$ in Pakistan 6 .

Depression is defined as a mood disorder whose primary symptoms are depressive, loss of interest or anhedonia, and loss of energy characterized by fatigue complaints in the 1993 Mental Disorder Classification and Diagnosis (PPDGJ-III) Guideline. The main symptoms are accompanied by additional symptoms such as decreased concentration, decreased self-esteem or self-confidence, feeling of worthlessness or guilt, have a bleak view of the future and pessimistic outlook, the emergence of the ideas of self-harm or suicide, sleep disturbance, and appetite depletion? ${ }^{7}$.

There is a reciprocal relationship between depression and diabetes. Diabetes increases the risk of depression, while depression also increases the risk of developing diabetes. Major depression will accelerate the onset of $\mathrm{T}_{2} \mathrm{DM}^{8}$. Diabetic patients that initially had no symptoms of depression have a greater chance of experiencing depression during the treatment period ${ }^{9}$.

The American Diabetic Association (ADA) recommends routine screening for psychosocial problems such as eating disorders, anxiety, and depression in DM management ${ }^{10}$. The condition of depression in DM patients is at the risk of reducing patient adherence to therapy ${ }^{11}$. This will increase the incidence of micro and macrovascular complications, disability, and mortality ${ }^{12}$. Therefore, efforts are needed to detect risk factors for depression in DM patients. In addition to continuous and multi-specialist treatment, education, patient self-management, and family support are needed by DM patients ${ }^{13}$.

The family has an important role in curing diseases, especially chronic diseases. A family function assessment in patients with chronic disease is essential to do by family doctors. It aims to make therapeutic planning as well as help the family to overcome the problems faced ${ }^{14}$.

The goal of APGAR is to gather family members about family functions by checking their satisfaction with family relationships. The conceptual organization consists of five parameters of family function: Adaptation, Partnership, Growth, Compassion, and Completion. Appearance, Pulse, Grimace, Activity, and Respiration (APGAR) is used in this research because, in addition to having good reliability and validity, this questionnaire is easy and quickly done so widely used in primary services ${ }^{15,16}$. In this study, we aimed to determine the effect of family APGAR scores on the incidence of depression in patients with T2DM in firstlevel health facilities.

\section{RESEARCH METHODS}

This study was a quantitative analytic research with a cross-sectional design. The subjects of this study were T2DM patients who regularly visited the health centers in Bantul district of Yogyakarta, namely Sedayu 1 Primary
Health Care Center, Sedayu 2 Primary Health Care Center, Kasihan 1 Primary Health Care Center, Kasihan 2 Primary Health Care Center, Banguntapan 1 Primary Health Care Center, and Kretek Primary Health Care Center. The sample selection was done by convenient sampling.

The sample size is calculated by using formula below ${ }^{17}$ :

$$
n=\frac{Z_{\alpha}^{2} P Q}{d^{2}}
$$

$$
\begin{array}{ll}
n & =\text { number of samples } \\
\alpha & =\text { significance level set } 0.01 \\
Z_{\alpha} & =\text { normal raw deviation for } \alpha=2.576 \\
P & =\text { the proportion of depression in diabetes }=30 \%{ }^{18} \\
Q & =1-P=0.7 \\
d & =\text { the level of absolute accuracy desired }=0.10
\end{array}
$$

$$
\begin{aligned}
& \text { Result }: \\
& \begin{aligned}
n & =\frac{Z_{\alpha}{ }^{2} P Q}{d^{2}} \\
n & =\frac{(1.96)^{2} \times 0.3 \times 0.7}{0.10^{2}} \\
& =80.6736 \\
& \approx 81
\end{aligned}
\end{aligned}
$$

The specified inclusion criteria were:

1) Patient with type II DM;

2) Aged 18 - 80 years;

3) Having blood glucose record for the last three months;

4) Able to speak Indonesian; and

5) Willing to complete the research.

While the exclusion criteria were:

1) Have a hearing loss; and

2) Have cognitive impairment.

This research consisted of two variables which are the independent variable and dependent variable. The independent variable was the family APGAR score of a score of 0 to $10^{15}$, while the dependent variable of this study was the level of depression in patients with T2DM, measured using HADS questionnaires for depression with a score of 0 to $21^{19}$. The confounding variables in this study were age, sex, BMI, duration of pain, blood sugar control, complications, and comorbidities.

Data collection of this study used three types of questionnaires. The first questionnaire (A) contained questions about the socio-demographic data and the history of the respondent's disease. The second questionnaire (B) was a family APGAR questionnaire to measure the family function ${ }^{15}$. The third (C) was the HADS questionnaire (Hospital Anxiety and Depression Scale) which was used to measure the depression level of T2DM patients ${ }^{19}$. Researchers have tested the validity of the HADS questionnaire and the APGAR Questionnaire that has been translated into Bahasa Indonesia. Both questionnaires have correlation coefficient (r) greater than correlation coefficient table $\left(\mathrm{r}_{\text {table }}\right)$ and have alpha values of 0.8380 and 0.8137 .

The data was completed by doing an interview. Questions 
on the questionnaire were read by the data-taker, a functional physician who had received a family physician training in the Faculty of Medicine, Public Health and Nursing, Universitas Gadjah Mada, and had received a briefing on the data collection procedures before the study began.

The family APGAR questionnaire and HADS used in this study had a cross-cultural adaptation to maintain the validity of the questionnaire concepts after it had been translated. The trial of the Indonesian version of family APGAR questionnaire and HADS with 30 respondents resulted that both questionnaires were quite valid and reliable to be used in the study. These results were consistent with the pre-existing studies ${ }^{15,20}$. To ensure understanding of the respondents to the questions on the family APGAR questionnaire, the researcher also added the question about "how much do you think is your family's role in supporting the DM treatment process?" This question explored the level of respondent's satisfaction from his family's support. The answer to that question was a scale of 1 to 10 .

Linear regression statistical tests were used to determine the effect of family APGAR scores on depression level in T2DM patients and to know the factors that play a role in the incidence of depression. Data processing in this research used the SPSS 17 program.

\section{RESULTS}

The study included 98 respondents. The obtained results were shown in the following tables. Table 1 shows the basic characteristics of respondents. Most of the respondents were women. The highest education level of respondents was high school graduates. The income level was mostly between one and less than three million rupiahs. More than half of the respondents were 45 to 59 years old. A total of 35 respondents were obese, and five people had smoked.

Table 1. Frequency distribution of respondents according to baseline characteristics

\begin{tabular}{|c|c|c|c|}
\hline No & Characteristics & Frequency & Percentage \\
\hline \multirow[t]{3}{*}{1.} & Sex & & \\
\hline & Male & 33 & 33.7 \\
\hline & Female & 65 & 66.3 \\
\hline \multirow[t]{5}{*}{2.} & Education Level & & \\
\hline & Elementary School & 23 & 23.5 \\
\hline & Junior High School & 23 & 23.5 \\
\hline & Senior High School & 33 & 33.7 \\
\hline & University & 19 & 19.4 \\
\hline \multirow[t]{4}{*}{3.} & Income & & \\
\hline & $<1$ million & 33 & 33.7 \\
\hline & 1 to $<3$ million & 41 & 41.8 \\
\hline & 3 to $<5$ million & 19 & 19.4 \\
\hline \multirow[t]{4}{*}{4.} & Age & & \\
\hline & $<45$ years & 8 & 8.2 \\
\hline & $45-59$ years & 51 & 52.0 \\
\hline & $>60$ years & 39 & 39.8 \\
\hline \multirow[t]{3}{*}{5.} & BMI & & \\
\hline & Obese & 35 & 35.7 \\
\hline & Normal & 63 & 64.3 \\
\hline \multirow[t]{3}{*}{6.} & Smoking & & \\
\hline & Yes & 5 & 5.1 \\
\hline & No & 93 & 94.9 \\
\hline
\end{tabular}

Table 2 shows the duration of illness and the respondents' control of blood sugar level. Most of the respondents were diagnosed with $\mathrm{DM}<5$ years ago. A total of $31 \%$ of respondents had an uncontrolled blood sugar level, while $67 \%$ of respondents had a controlled blood sugar level. Almost all patients chose OAD treatment $(92.9 \%)$, while the rest wanted insulin treatment $(6.1 \%)$, and alternative treatment $(1 \%)$. Majority of the patients were without complications $(65.3 \%)$, and only a small proportion had complications (34.7\%). The complications were peripheral neuropathy $(19.4 \%)$, stroke $(4 \%)$, ulcers $(4 \%)$, cataract $(2 \%)$, retinopathy $(3 \%)$, nephropathy $(3 \%)$, and coronary heart disease $(1 \%)$. More than half of the respondents had comorbidities. The comorbidities encountered with the study sample were hypertension, obesity, and joint pain. Most of the respondents had more than one family members $(75.5 \%)$, and the rest only had one family member $(24.5 \%)$.

The results of the family APGAR score assessment are shown in Figure 1. Most patients had a family APGAR score of 10. Four people had a score of 0 . The rest had the score of 2 to 9 . No one had a score of 1 .

Figure 2 shows the level of depression measured by the HADS questionnaire. As many as 27 respondents had a score of 0 , one person had a score of 11 , and the rest had the score of 1 to 9 . No respondents had the score of 10 and 12 to 21 .

APGAR score relationship and depression score were analyzed using Spearman correlation statistic test. The sig value of Spearman correlation test showed $<0,05$, so it can be concluded that there is a relationship between APGAR 
Table 2. Frequency distribution of respondents according to the duration of illness andcontrol of blood sugar level, type of treatment, presence/absence of complications

\begin{tabular}{|c|c|c|}
\hline Variable & Frequency & Percentage \\
\hline \multicolumn{3}{|l|}{ Duration } \\
\hline$<5$ years & 57 & 58.2 \\
\hline $5-10$ years & 29 & 29.6 \\
\hline$>10$ years & 12 & 12.2 \\
\hline \multicolumn{3}{|l|}{ Blood glucose level } \\
\hline Controlled & 31 & 31.6 \\
\hline Uncontrolled & 67 & 68.4 \\
\hline \multicolumn{3}{|l|}{ Type of Treatment } \\
\hline $\mathrm{OAD}$ & 91 & 92.9 \\
\hline Insulin & 6 & 6.1 \\
\hline Alternative & 1 & 1.0 \\
\hline \multicolumn{3}{|l|}{ There are complications } \\
\hline Peripheral neuropathy & 19 & 19.4 \\
\hline Stroke & 7 & 4 \\
\hline Ulcus & 4 & 4 \\
\hline Cataract & 3 & 2 \\
\hline Retinopathy & 4 & 3 \\
\hline Nephropathy & 3 & 3 \\
\hline Coronary Heart Disease & 1 & 1 \\
\hline No complications & 64 & 65.3 \\
\hline \multicolumn{3}{|l|}{ There are comorbidities } \\
\hline Hypertension & 16 & 16 \\
\hline Obesity & 35 & 35.7 \\
\hline Arthralgia & 1 & 1 \\
\hline No comorbidities & 46 & 47 \\
\hline
\end{tabular}

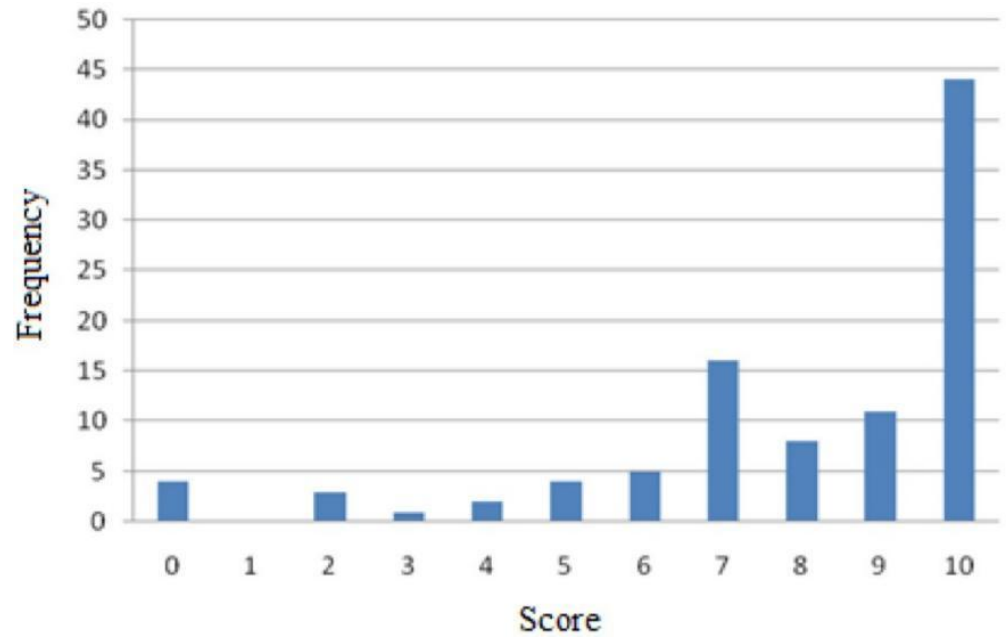

Figure 1. Frequency distribution of respondents according to family APGAR score

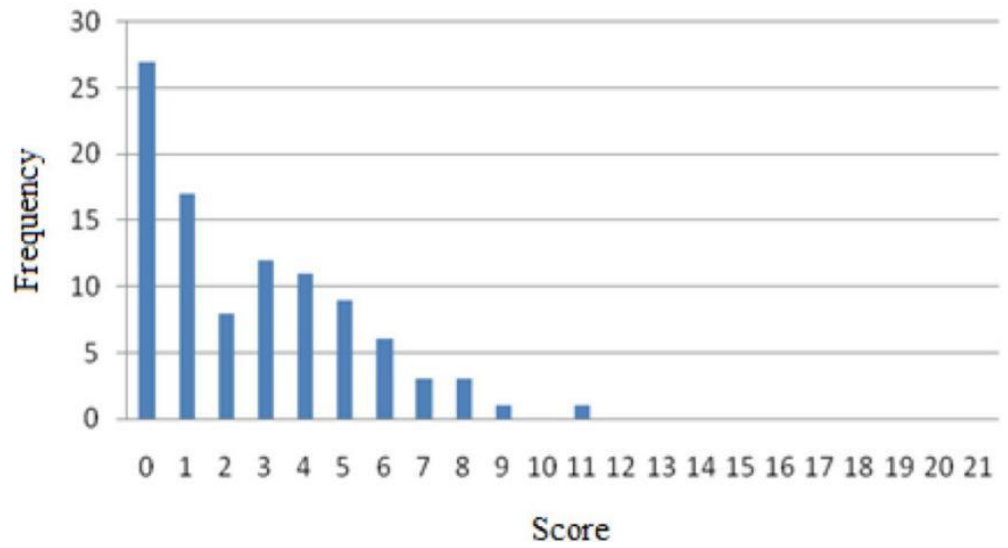

Figure 2. Frequency distribution of respondents according to depression level 
score and depression score with correlation strength ($0,364)$.

The effects of family APGAR score, sex, age, BMI, complications, co-morbidity, and blood sugar control on depression score were tested using linear regression statistical analysis. Analysis using backward method showed a significant effect of family APGAR scores and age to depression scores with sig $<0.05(0.000)$.

The obtained regression equation was:

$\mathrm{Y}=$ constant $+\mathrm{a}_{1} \mathrm{x}_{1}+\mathrm{a}_{2} \mathrm{x}_{2}+\ldots \mathrm{a}_{\mathrm{i}} \mathrm{x}_{\mathrm{i}}$

Depression $=13.003-0.106($ age $)-0.371($ APGAR $)$

The above equation was used to estimate the depression score.

Example: the known age of the patient is 51 years, and the family APGAR score of 10. By using the above equation, the prediction value of the patient's depression scores as follows:

$$
\begin{aligned}
\text { Depression score } & =13.003-0.106(51)-0.371(10) \\
\text { Depression score } & =13.003-5.046-3.71 \\
& =3.887 \\
& =4
\end{aligned}
$$

The ANOVA tests for the above equation showed the sig value $<0.005(0.002)$ so that the above equation was considered feasible to estimate the depression score. The family APGAR score and age contributed 10.6\% in predicting depression. The remaining $89.4 \%$ was explained by other variables that were not assessed in this study.

The result of the statistical analysis showed a significant effect of family APGAR scores on depression, with correlation strength $(-0.364)$. This result suggested that an increase in family APGAR score in patients with T2DM will decrease the depression score by 0.364 times.

\section{DISCUSSIONS}

According to research from Oliveira et al., respondents that had a dysfunctional family function (family APGAR score 0-3) were more at risk of showing depressive symptoms than respondents with functional families ${ }^{21}$.

Multivariate analysis of factors affecting depression showed that family APGAR scores and age had a significant effect on depression score. The family APGAR score and age contributed $10.6 \%$ to the depression score. The higher the family APGAR score and the increasing age, will lower the depression score. This conclusion was in line with Egede et al. in their study, which concluded that young age was a risk factor for the emergence of depression in diabetic patients ${ }^{22}$.

Diabetes patients have a risk of developing symptoms of depression as a result of psychosocial problems or as the complications of diabetes itself. Taking the status of a diabetic patient brings several impacts on the patient such as lifestyle changes, regular medication for a lifetime, repeated visits to the doctor and decreased function due to complications. It will cause some emotional responses, one of which is depression ${ }^{23}$.

A systemic review of the biological mechanisms of depression and T2DM stated that inflammatory processes were suspected to be the conditions that bridge these two diseases. Depression and DM have a pathogenesis that both involve the inflammatory process. Depression is known to be associated with impaired function of the hypothalamus-pituitary-adrenal axis (HPA), neurotrophin, neurotransmitters, and inflammatory mediators ${ }^{24}$.

Diabetes is characterized by conditions of insulin resistance and hyperglycemia. Insulin resistance results in hyperinsulinemia. Iwasaki et al. concluded that short-term insulin would have anti-inflammatory effects, but longterm insulin exposure would have a pro-inflammatory effect through inhibition and stimulation of NF-kB. While hyperglycemia has been widely investigated to have a proinflammatory effect through the production of Reactive Oxygen Species $(\mathrm{ROS})^{25}$. Also, one of the factors that trigger T2DM is obesity or body fat accumulation, which has been shown to be an independent factor for depression trigger ${ }^{26}$. Thus, diabetes and obesity will lead to increase factors of inflammation, hyperglycemia, and hyperinsulinemia. This cycle will create a pro-inflammatory state in some body tissues. The ability of inflammatory mediators to reach the central nervous system will trigger depressive symptoms ${ }^{24}$.

Neurotrophic agents allegedly also play a role in the occurrence of depression. Brain-Derived Neurotrophic Factor (BDNF) is a neurotrophic agent functioning in the regulation of neuronal growth. The decrease in BDNF production is thought to affect the incidence of depression. Krabbe et al. found low levels of BDNF in patients with T2DM and patients with obesity. BDNF is estimated to have a role in the regulation of glucose ${ }^{27}$.

Diabetes affects not only the patient but also the family. Family response to the diagnosis of diabetes will affect the patient. A very caring family will always try to be involved in arranging treatment and healthy lifestyle for the patient. This potentially makes the patient less depressed. In contrast, a careless family will cause the patient to feel lonely and worthless ${ }^{24}$.

Depression in diabetes is critical to be managed because it will worsen the patient's condition. Lustman et al. concluded with a meta-analysis study that depression was significantly associated with poor blood sugar control, both in T1DM and $\mathrm{T}_{2} \mathrm{DM}^{28}$. Diabetic complications such as retinopathy, nephropathy, neuropathy, microvascular complications, and sexual dysfunction are also more common in diabetic patients with depression ${ }^{29}$. Additionally, depression in diabetic patients is also significantly associated with increased disability and mortality ${ }^{30}$.

This study reinforces recommendations of doctors that are for the first-level health facilities to routinely assess family functions using family APGAR scores. This approach is an attempt to recognize the risk factors of depression in patients 
with T2DM so that proper management can be done. It is expected that the risk of deterioration of diabetes can be prevented and lowered by early interventions.

Data retrieval of this research involved several data resources so that bias could occur. To solve this problem, the researcher tried to do interrater tests. The result of this test was quite good for the coefficient kappa $=0.230$ and 0.537 with the $p$ value $>0.05$. This means that between researchers and data takers there was the same agreement in analyzing the data obtained.

This research had several weaknesses. First, most (87.8\%) of the respondents in this study were diagnosed with T2DM for less than ten years. Only $12.2 \%$ had diabetes for more than ten years. The risk of new depression will increase almost two-fold in patients with DM for ten years, while those who have DM for three decades have a three-fold risk ${ }^{31}$.

Patients diagnosed with diabetes for less than ten years may still be at the beginning of the Kubler-Ross grief process, and have not reached the stage of depression. Kubler-Ross explained that a person diagnosed with an illness would experience a series of psychological stages of rejection, anger, bargaining, depression, and finally acceptance $^{23}$. Not all diabetic patients experience these five stages. Some people may wrestle with one stage for years, or even jump back to the previous stage without completing the five stages. DM patients that are constantly in the depression stage can potentially harm their physical and mental condition. Therefore, this stage must be passed, and finally, the patients reach the self-acceptance stage.

Second, the research sampling took place at primary health care centers. This sample determines the number of cases of depression encountered. Respondents in this research were DM patients that routinely came to the primary health care center. It means that the patients are consciously seeking treatment for their illness. On the other hand, DM patients that are depressed will tend to be disobedient to the treatment ${ }^{32}$. Different results may be obtained if the study is conducted in a different population or in the referral hospital.

Third, the family APGAR questionnaire used in this study consisted of 5 positive statements for which each of them had three alternatives answers in the form of intervals, i.e., often, occasionally, and infrequently. The weakness for a research instrument with all positive statements is that respondents are more likely to choose the answers in the same column ${ }^{33}$.

The recheck question on the family APGAR questionnaire was also tested statistically. The result was that the recheck question had a significant relationship to the result of the family APGAR score. This finding reinforces the notion that what is measured by the family APGAR questionnaire is the level of respondent's satisfaction with his family, rather than directly assessing the function of a family ${ }^{34}$.

Assessment of a family function should be routinely performed in patients with diabetes, especially those at a young age because there is a tendency for increased risk of depression. The family APGAR questionnaire that has been validated and modified as in this study can be used as an easy and simple measuring tool to assess family function in T2DM patients in first-level health facilities.

The researchers encourage the study of depression prevalence in DM patients in Indonesia. Early diabetes screening is essential to prevent worsening of preventable conditions suffered by the patients.

\section{CONCLUSION}

From this research, we concluded that family APGAR scores had a significant effect on depression level. Family APGAR scores and age contributed $10.6 \%$ to depression. The higher the family APGAR score of T2DM patients, the lower the incidence of depression. Age factor plays the opposite role. Depression is more likely to occur in younger DM patients.

\section{Acknowledgment}

Our greatest thanks to doctors at Primary Health Care Center of Sedayu I, Sedayu II, Kasihan 1, Kasihan 2, Banguntapan 1, and Kretek who had helped in this research.

\section{Ethical Approval and Informed Consent}

This study was approved by the Medical and Health Research Ethical Committee (MHREC) from the Faculty of Medicine, Public Health and Nursing, Universitas Gadjah Mada, Yogyakarta with reference number KE/ FK/1371/EC/2015.

\section{Funding}

Self-funding.

\section{Availability of Data and Materials}

Please contact the author for the availability of data and material through the author's correspondence.

\section{Conflict of Interest}

None.

\section{REFERENCE}

1. Wild S, Roglic G, Green A, Sicree R, King H. Global prevalence of diabetes: Estimates for the year 2000 and projections for 2030 . Diabetes Care. 2004 May 1;27(5):1047-53.

2. Ministry of Health Research and Development Agency. Basic health research. Jakarta: Ministry of Health, Republic of Indonesia. 2013.

3. Anderson RJ, Freedland KE, Clouse RE, Lustman PJ. The prevalence of comorbid depression in adults with diabetes: A meta-analysis. Diabetes Care. 2001 Jun 1;24(6):1069-78.

4. Collins MM, Corcoran P, Perry IJ. Anxiety and depression symptoms in patients with diabetes. Diabetic Medicine. 2009 Feb 1;26(2):15361

5. Asghar S, Hussain A, Ali SM, Khan AK, Magnusson A. Prevalence of depression and diabetes: A population-based study from rural Bangladesh. Diabetic medicine. 2007 Aug 1;24(8):872-7.

6. Zahid N, Asghar S, Claussen B, Hussain A. Depression and diabetes in a rural community in Pakistan. Diabetes research and clinical practice. 2008 Jan 1;79(1):124-7.

7. Maslim R. Pocket book version: Diagnosis of mental disorder (PPDGJ-III). Jakarta: Faculty of Psycho Medicine Unika Atmajaya. 2004.

8. Eaton WW, Armenian H, Gallo J, Pratt L, Ford DE. Depression and risk for onset of type II diabetes: A prospective population-based study. Diabetes Care. 1996 Oct 1;19(10):1097-102. 
9. Golden SH, Lazo M, Carnethon M, Bertoni AG, Schreiner PJ, Roux $\mathrm{AV}$, Lee HB, Lyketsos C. Examining a bidirectional association between depressive symptoms and diabetes. Jama. 2008 Jun 18;299(23):2751-9.

10. American Diabetic Assosiation. Standard of Medical Care in Diabetes. Diabetes Care. 2015; 38(1), 510-93.

11. DiMatteo MR, Lepper HS, Croghan TW. Depression is a risk factor for noncompliance with medical treatment: Meta-analysis of the effects of anxiety and depression on patient adherence. Archives of Internal Medicine. 2000 Jul 24;160(14):2101-7.

12. Black SA, Markides KS, Ray LA. Depression predicts increased incidence of adverse health outcomes in older Mexican Americans with type 2 diabetes. Diabetes Care. 2003 Oct 1;26(10):2822-8.

13. American Diabetic Association. Standard of medical care in diabetes. Diabetes Care. 2010;33(Suppl 1):511-561.

14. McWhinney IR. A textbook of family medicine. New York: Oxford University Press. 1997.

15. Smilkstein G. The Family APGAR: A proposal for family function test and its use by physicians. The Journal of Family Practice. 1978;6(6):1231-9.

16. Shortridge-Baggett LM. Structured evaluation method for family assessment tools: Evaluation of the family APGAR. Fam. Saúde Desenv. 2004;6(2):91-99.

17. Madiyono B, Moeslichan S, Sastroasmoro S, Budiman I, Purwanto SH. Perkiraan besar sampel. Dasar-dasar metodologi penelitian klinis. Jakarta: Sagung Seto, 2002; p. 259-86.

18. Asghar S, Hussain A, Ali SM, Khan AK, Magnusson A. Prevalence of depression and diabetes: A population-based study from rural Bangladesh. Diabetic Medicine. 2007 Aug 1;24(8):872-7.

19. Zigmond AS, Snaith RP. The hospital anxiety and depression scale. Acta Psychiatrica Scandinavica. 1983 Jun 1;67(6):361-70.

20. Bjelland I, Dahl AA, Haug TT, Neckelmann D. The validity of the Hospital Anxiety and Depression Scale: An updated literature review. Journal of Psychosomatic Research. 2002 Feb 1;52(2):69-77.

21. Oliveira SC, Santos AA, Pavarini SC. The relationship between depressive symptoms and family functioning in institutionalized elderly. Revista da Escola de Enfermagem da USP. 2014 Feb;48(1):65-71.

22. Egede LE, Zheng D. Independent factors associated with a major depressive disorder in a national sample of individuals with diabetes. Diabetes Care. 2003 Jan 1;26(1):104-11.

23. Nash J. Understanding the psychological impact of diabetes and the role of clinical psychology. Journal of Diabetes Nursing. 2014;18: 137-42.

24. Stuart MJ, Baune BT. Depression and type 2 diabetes: Inflammatory mechanisms of a psychoneuroendocrine co-morbidity. Neuroscience \& Biobehavioral Reviews. 2012 Jan 1;36(1):658-76.

25. Iwasaki Y, Nishiyama M, Taguchi T, Asai M, Yoshida M, Kambayashi M, Terada Y, Hashimoto K. Insulin exhibits short-term anti-inflammatory but long-term proinflammatory effects in vitro. Molecular and Cellular Endocrinology. 2009 Jan 27;298(1-2):25-32.

26. Luppino FS, de Wit LM, Bouvy PF, Stijnen T, Cuijpers P, Penninx BW, Zitman FG. Overweight, obesity, and depression: A systematic review and meta-analysis of longitudinal studies. Archives of GeneralPsychiatry. 2010 Mar 1;67(3):220-9.

27. Krabbe KS, Nielsen AR, Krogh-Madsen R, Plomgaard P, Rasmussen P, Erikstrup C, Fischer CP, Lindegaard B, Petersen AM, Taudorf S, Secher NH. Brain-derived neurotrophic factor (BDNF) and type 2 diabetes. Diabetologia. 2007 Feb 1;50(2):431-8.

28. Lustman PJ, Anderson RJ, Freedland KE, De Groot M, Carney RM, Clouse RE. Depression and poor glycemic control: A meta-analytic review of the literature. Diabetes Care. 2000 Jul 1;23(7):934-42.

29. De Groot M, Anderson R, Freedland KE, Clouse RE, Lustman PJ. Association of depression and diabetes complications: A metaanalysis. Psychosomatic Medicine. 2001 Jul 1;63(4):619-30.

30. Egede LE, Ellis C. Diabetes and depression: Global perspectives Diabetes Research and Clinical Practice. 2010 Mar 1;87(3):302-12.

31. Davenport L. J-shaped link between diabetes duration and depression. Maturitas [serial online]. 2016.

32. DiMatteo MR, Lepper HS, Croghan TW. Depression is a risk factor for noncompliance with medical treatment: a meta-analysis of the effects of anxiety and depression on patient adherence. Archives of
Internal Medicine. 2000 Jul 24;160(14):2101-7.

33. Widoyoko EP. Technique preparation of research instruments. Yogyakarta: Pustaka Pelajar. 2012.

34. Apostol-Nicodemus L, Umali M. Family assessment tools and their application in family practice. In Textbook of family medicine, principle, concepts, practice, and context. C\&E Publishing, Inc and the Philippine Academy of Family Physicians. 2014. 